\title{
Getting More Organs for Transplantation
}

\section{Citation}

Kessler, Judd B., and Alvin E. Roth. 2014. "Getting More Organs for Transplantation." American Economic Review 104 (5) (May): 425-430. doi:10.1257/aer.104.5.425.

\section{Published Version}

10.1257/aer.104.5.425

\section{Permanent link}

http://nrs.harvard.edu/urn-3:HUL.InstRepos:30208846

\section{Terms of Use}

This article was downloaded from Harvard University's DASH repository, and is made available under the terms and conditions applicable to Open Access Policy Articles, as set forth at http:// nrs.harvard.edu/urn-3:HUL.InstRepos:dash.current.terms-of-use\#OAP

\section{Share Your Story}

The Harvard community has made this article openly available.

Please share how this access benefits you. Submit a story.

\section{Accessibility}


Title: Getting More Organs for Transplantation

Authors: Judd B. Kessler and Alvin E. Roth

Judd B. Kessler (corresponding author): Department of Business Economics and Public Policy, The Wharton School, University of Pennsylvania, Philadelphia, PA 19104;

judd.kessler@wharton.upenn.edu

Alvin E. Roth: Department of Economics, Stanford University, Stanford, CA 94305;

alroth@stanford.edu

Session Title: Frontiers of Market Design

Session Chair: Alvin E. Roth

Discussants: Michael Ostrovsky (Stanford University) (ostrovsky@gsb.stanford.edu)

James Andreoni (University of California, San Diego) (andreoni@ucsd.edu)

Ilya Segal (Stanford University) (ilya.segal@stanford.edu)

Larry Samuelson (Yale University) (larry.samuelson@yale.edu) 
The United States and most other nations suffer from a shortage of human organs for transplant. In the U.S. over 120,000 people are on waiting lists for organ transplant, and every year over 10,000 people die while waiting (OPTN). There are a number of fronts on which research has made progress to address this shortage, but there is still significant work to be done. We describe how organs are acquired and allocated, strategies that have been implemented to increase the number or organ donations for transplantation from living donors, and work we are conducting to understand how we can recover more organs from deceased donors. For example, how organs are allocated can moderate their scarcity, not just through efficiencies in allocation but also through changes in donor behavior. We will describe a market design being explored in Israel to increase organ donor registration by providing priority on organ waiting lists for individuals who previously registered as organ donors. We will also report results that raise concern over policies that have recently been implemented in the U.K. and several U.S. states, namely changing the way the organ registration question is asked to a "mandated choice" frame.

Organs for transplant can be recovered from living donors and deceased donors. Living donors give an organ while alive. Living donation of kidneys, which represented $96 \%$ of all U.S. living organ donations in 2012 (OPTN), is possible since humans have two kidneys but can live a healthy life with only one, allowing the other to be removed and donated. The vast majority of these living donors make directed donations: they donate the organ to a pre-specified recipient, usually a family member. There are relatively rare instances of non-directed donation, where an individual donates to whomever needs an organ; just over $3 \%$ of living donor kidneys in the U.S. came from non-directed donors in 2012 (Cook and Krawiec 2013).

Deceased donors are individuals whose organs are donated at the time of their death. The majority of organ donors are deceased donors ( $58 \%$ in 2012 when there were 8,143 deceased 
donors and 5,867 living donors, OPTN). In addition, since each deceased donor can donate multiple organs, the large majority of organs are recovered from deceased donors ( $81 \%$ of all organs for transplant in 2012, OPTN). The Uniform Anatomical Gift Act requires consent for deceased donation, either by the individual having previously registered as an organ donor or by the deceased's next of kin. Organ donor registration usually takes place at state departments of motor vehicles, and despite the relative ease of becoming an organ donor - usually just checking a box or signing a form — only 43\% of Americans are registered (Donate Life 2012). Many additional organs are recovered when next of kin consent to donation on behalf of unregistered deceased. (Next of kin are also asked to consent to donation of registered donors. While this conformation is not deemed to be legally necessary to proceed with donation, it is usually done anyway, Glazier 2011). That next of kin play an important role means that registration and transplantation are not identical, which is going to be important when we discuss priorities for registration and mandated choice.

Organs that are made available for transplant save lives and lower medical costs. For organs like the liver and the heart, patients who do not receive an organ for transplant when they need one often have short life expectancy. Individuals with kidney failure can survive for a number of years on dialysis, but they live 10 years longer on average if they receive an organ from a deceased donor (Wolfe 1999). Receiving a living donor kidney likely generates additional life years since the average living donor kidney lasts substantially longer than a deceased donor kidney. In addition, dialysis costs Medicare about $\$ 90,000$ a year while transplantation costs $\$ 100,000$ for the surgery plus $\$ 20,000$ a year for immunosuppressive drugs (i.e. an out of pocket savings of $\$ 250,000$ per transplant over the first five years, see Rees et al. 2012).

With such significant gains coming from organ donation and transplantation, the excess 
demand for organs is an important policy problem. One standard first response by economists is that we can solve excess demand by raising the price from the current legal limit of zero by allowing organs to be bought and sold, potentially for both living and deceased donation (see e.g. Becker and Elias 2007). However this is not easy to implement, since many countries have strict legislation against such transactions (in the United States it is a felony under the National Organ Transplant Act of 1984). Roth (2007) uses the term "repugnant transaction" to denote transactions that some people would like to engage in but which others think should not be allowed, and shows that these have a long and varied history that changes in time and place (e.g. charging interest on loans, indentured servitude, selling horsemeat for human consumption, and same-sex marriage all have been repugnant transactions in some times and places and not in others). Kidney sales are often the leading example of a repugnant transaction cited by those who would put stricter limits on markets in general (e.g. Sandel 2012, 2013), because of their sense that such sales arouse widespread opposition. A representative sample survey of Americans conducted by Leider and Roth (2010) suggests that disapproval of kidney sales correlates with other socially conservative attitudes, but that it does not rise to the level of disapproval of other repugnant transactions such as prostitution. In addition, there is evidence that the manner of the payment to an organ donor may mitigate some of the repugnance concerns. Niederle and Roth (forthcoming 2014) find that payments to non-directed kidney donors are deemed more acceptable when they arise as a reward for heroism and public service than when they are viewed as a payment for kidneys.

The particular interest in donations from non-directed donors arises because of the large effect they have on facilitating other live-donor transplants, through the mechanism of kidney exchange, which arose in the last decade as an effective means of promoting transplantation even 
when donors and their intended recipients are biologically incompatible (see Roth et al 2004, 2005 for early proposals that have led to large-scale implementation). As kidney exchange began to assemble pools of patient-donor pairs, it became possible to offer non-directed donors the possibility of initiating a long chain of donations, in which the non-directed donor would donate to the patient in an incompatible pair, whose donor would donate to another pair, and so on (see e.g. Roth et al. 2006 for the suggestion that such chains could be made long by being nonsimultaneous, and Rees et al. 2009 for the report of the first non-simultaneous chain which at the time of the report facilitated ten transplants, and subsequently grew to sixteen). In total there have been over 2,500 paired donation kidney transplants performed in the U.S. since the year 2000 , when the first two transplants of that kind were performed. Not only do long chains make more efficient use of the otherwise unavailable kidneys from willing donors who are incompatible with their intended recipients, it appears that the possibility of initiating a long chain and facilitating multiple transplants may inspire additional non-directed donors.

While kidney exchange has increased the number of living donor transplants, the waiting list for transplants continues to grow, underscoring the need to explore other avenues, for example strategies to increase the number of deceased donor organs available for transplant. As for living organ donation, legislation in the U.S. and most other nations prohibits the use of monetary payments as an inducement for deceased organ donation. Consequently, one promising approach has been to create non-monetary incentives for deceased donation. Singapore and, more recently, Israel have introduced allocation schemes that provide priority on organ donor waiting lists to individuals who have previously registered as donors. Since organ donor waiting lists can often be quite long (e.g. the average wait time on the list for a kidney in the U.S. is over 4 years, OPTN) and receiving an organ for transplant sooner is usually preferable to the 
alternative (e.g. remaining on dialysis), receiving priority on a waiting lists if an individual ever needs an organ can be an actionable incentive to register.

Whether such policies are effective at generating new donors will require an analysis of empirical data. Early indications of success are promising (Lavee et al. 2013), but it will take time for individuals to decide whether to register and to see whether the increase in registration leads to the desired increase in organs for transplant (a gap between these may arise for reasons we will address below). In the meantime, we can use laboratory experiments to better understand the priority architecture that has been implemented in Israel and how it might be implemented in other countries.

Our first project on priority allocation investigated whether such a rule would increase registration and the mechanisms that might generate an effect (Kessler and Roth 2012). We designed a laboratory game modeled on the decision to register as an organ donor, in which subjects could pay a monetary cost (meant to model the psychic cost of registering as a organ donor) that would allow his assets (meant to model kidneys) to be donated to other subjects in the lab who needed them to earn money once the assets were no longer of use to the donor (meant to model deceased donation). We compared treatments where allocation of available assets was made in a first-come, first-served basis (meant to model the current U.S. allocation system) to a treatment where those who agreed to paid the cost to donate their assets received priority for any donated assets that became available. The priority allocation rule led to a large, significant increase in donation. Additional treatments revealed that the main mechanism driving this increase was the monetary incentive effect of priority; the same increase in donation was induced by providing a rebate for donation equal to the expected value of having priority or by lowering the cost of donation by the expected value of having priority. 
While our first experiment investigated the reasons priority might work to increase organ donations, it made a simplifying assumption that we investigated in follow-up work. Namely, it assumed that the allocation rule could be implemented so that everyone who registered as an organ donor to receive priority would actually donate when in a position to do so. However, the implementation of the priority rule in Israel suggests this assumption may not hold true. The Israeli donor registration card, which one must sign to receive priority, has a check box that requires a clergyman chosen by the deceased's family to approve the donation at the time of death. This check box has the potential to operate as a loophole in the priority allocation system whereby an individual signs a donor card to receive priority on the waiting list if he is ever in need of an organ but expects his family or clergyman to decline the donation if he dies and is in a position to donate. Essentially it allows individuals to receive priority even though they would never make a donation.

In a second laboratory study, we investigate how such a loophole might affect the ability of the priority system to increase donation as well as registration (Kessler and Roth, forthcoming 2014). First, we replicate the effect of the priority rule we identified in our previous work (despite changing the parameters of the laboratory study in a number of ways). When registration leads automatically to donation, we again find that giving priority to individuals who register increases the number of organs made available for transplant. However, when we introduce a loophole in the priority system — allowing subjects to register for priority but not pay the cost of donation and so never donate — we find that the loophole completely eliminates the benefit of priority. Those subjects who might have been induced to donate by the incentive of receiving priority simply take priority without paying the cost of donation. Across all subjects in all rounds, $96 \%$ have priority when the loophole is available. 
We also find that introducing a loophole to a priority allocation system might do additional harm. In a set of treatments where we provide subjects with information about the costs and decisions of others (i.e. the distribution of costs of donation and distributions of choices to donate or to take the loophole in the previous round) we get fewer donations under a priority system with a loophole than under a first-come, first-served system without priority. This means that subjects who would have donated for altruistic or warm glow (Andreoni 1990) reasons choose not to donate when a loophole is available. Delving into the round-by-round data, we find that this effect appears to be driven by a conditional cooperation motive. Subjects are less likely to donate when they learn that others are choosing not to pay the cost of donation. However, subjects treat taking the loophole as a worse affront than simply not donating, presumably since those who take the loophole are explicitly abusing a system designed to reward donors. Consequently, subjects withhold donation more in response to observing others use the loophole than in response to observing others choosing not to donate. Only time will tell whether Israelis who do not want to donate will take advantage of the clergy check box as a loophole or how individuals might respond to such an abuse. In the meantime, our results highlight that the way priority is implemented matters a great deal for the success of such market designs.

While priority on organ donor waiting lists for registered donors might be possible to implement in the U.S., policy attention in recent years has focused instead on how individuals are asked to register as organ donors. U.S. states and many other countries maintain an opt-in registry whereby individuals are by default not organ donors but can choose to join the registry. An alternative, implemented by many European countries, presumes consent and gives individuals the opportunity to opt out of the organ donor registry. Johnson and Goldstein (2003, 2004) show that European countries that have opt-out systems have vastly higher donor 
registration rates than the European countries that have opt-in systems. The same authors find that in hypothetical choice data subjects indicate they would be more likely to remain on an organ donor registry in an opt-out system than to join an organ donor registry in an opt-in system. However, switching to an opt-out system has been deemed untenable in the U.S. since organ donation falls under gift law and so requires a positive statement of support in favor of donation (Glazier 2011). In addition, despite the higher rates of organ donor designation in the European countries that presume consent, only Spain has a higher per capita organ recovery rate than the U.S.. While Spain presumes consent, there is an indication that their high recovery rate is due to a more efficient organization of transplant services (Deffains and Ythier 2010).

Instead of moving to presumed consent, therefore, the predominant policy change in the U.S. has been to switch the organ donation registration question from an opt-in frame to a "mandated choice" frame (also called a "forced choice" or an "active choice" frame). Under an opt-in frame, the individual who is being asked to register, usually at a state department of motor vehicles, checks a box to register and leaves it blank not to register. Under a mandated choice frame, the organ donation request is framed as a "yes" or "no" question whereby answering yes adds the individual to the registry and answering no does not. This policy change has been recently implemented by a number of U.S. States (e.g. IL, CA, NY) as well as by the U.K..

While this switch to mandated choice has been pushed by organ donor advocates, the support for the policy comes from hypothetical choice data in which individuals were more likely to report being willing to join a registry when asked under a mandated choice with no prior default than when asked under an opt-in frame when individuals were presumed to not be donors (Johnson and Goldstein 2003, 2004). Additional results have come from the use of mandated choice in Illinois (Thaler 2009), which was implemented among other changes including 
simplifying the registration process and making organ donor registration legally binding.

In ongoing work, we are investigating whether the effect of framing the organ donor registration question as a mandated choice increases registration rates over an opt-in frame where individuals check a box to register and leave it blank not to register. Results from an experimental study of actual organ donor decisions on the Massachusetts Organ and Tissue Donor Registry suggest that the mandated choice frame may not deliver an increase in registrations as promised (Kessler and Roth 2013).

In addition, we find that mandated choice may have a negative effect on organ donation, even if it leaves organ donor registration unchanged. As discussed above, registrations are not the only way organs can become available for transplant; the organs of an unregistered deceased can be donated by surviving next of kin. In a hypothetical choice experiment we ask subjects to report whether they think next of kin should donate a deceased's organs. We show subjects the decision screen the deceased saw (either a mandated choice frame or an opt in frame) and indicate the choice made by the deceased (either to join the registry or not to join the registry). Subjects are less likely to report that next of kin should donate the organs of an unregistered deceased if the deceased explicitly said no to registration in a mandated choice framed question than if the deceased simply chose not to opt in. This suggests that asking individuals to register under a mandated choice frame may make it harder to get permission for organ donation from the next of kin of those who remain unregistered. This is particularly important because the historical data in Massachusetts suggests that over half of the unregistered donors have their organs recovered after next of kin give permission.

Kessler and Roth (2013) do find that providing a simple and convenient way for donors to change their organ donation status on the registry increases deceased donor registration, and 
so expanding the opportunities to do so under the current "opt-in" framework seems worth further exploration. However, note that while we see great potential in increasing the number of deceased donor organs available for transplant, there is a limit to the number of organs that can be recovered from this source alone. Since individuals need to die in a manner conducive to organ donation (e.g. die in a hospital, typically from an intracranial event) for the organs to be suitable for transplant, there is a bound on the number of potential donors. Estimates from 2010 suggest that organs are recovered from just over two thirds of eligible deaths, meaning there would have only been 3,000 additional donors if consent for donation were received for all eligible deaths (OPTN). While these potential donors could save thousands of additional lives, at current rates of medical need, these donors alone would not be able to supply all the demand. Consequently, we must continue working on numerous fronts to solve this growing problem.

Andreoni, James, 1990. Impure altruism and donations to public goods: a theory of warmglow giving. Econ. J. 100 (401), 464-477.

Becker, Gary S., and Julio Jorge Elias. "Introducing incentives in the market for live and cadaveric organ donations." The Journal of Economic Perspectives21.3 (2007): 3-24.

Cook, Philip J. and Kimberly D. Krawiec. 2013. A Primer on Kidney Transplantation: Anatomy of the Shortage. Working paper.

Deffains, Bruno and Jean Mercier Ythier. Optimal Production of Transplant Care Services. Journal of Public Economics 2010;94:638-53.

Donate Life America. National Donor Designation Report Card 2012. 2012. Richmond, VA: Donate Life America.

Glazier, Alexandra K. "The principles of gift law and the regulation of organ 
donation." Transplant International 24.4 (2011): 368-372.

Health Resources and Services Administration. 2011. "2011 Annual Data Report” (available at http://srtr.transplant.hrsa.gov/annual_reports/2011/default.aspx)

Johnson, Eric J. and Daniel G. Goldstein. Do Defaults Save Lives? Science 2003;302(5649):1338-9.

Johnson, Eric J. and Daniel G. Goldstein. Defaults and Donation Decisions. Transplantation 2004;78(12):1713-6.

Kessler, Judd B., and Alvin E. Roth. Organ Allocation Policy and the Decision to Donate. American Economic Review 2012;102(5):2018-47.

Kessler, Judd B., and Alvin E. Roth. Loopholes undermine donation: An experiment motivated by an organ donation priority loophole in Israel. Journal of Public Ecconomics, 2014.

Kessler, Judd B., Roth, Alvin E., 2013. Don’t Take 'No' For an Answer: An Experiment with Actual Organ Donor Registrations. Working paper.

Lavee, Jacob, Tamar Ashkenazi, Avi Stoler, J. Cohen, and R. Beyar. Preliminary Marked Increase in the National Organ Donation Rate in Israel Following Implementation of a New Organ Transplantation Law. American Journal of Transplantation 2013;13:780-5.

Leider, Stephen, and Alvin E. Roth. "Kidneys for sale: Who disapproves, and why?" American Journal of Transplantation 10.5 (2010): 1221-1227.

Niederle, Muriel and Alvin E. Roth. "Philanthropically Funded Heroism Awards for Kidney Donors?" Law \& Contemporary Problems, 77:3, forthcoming, 2014.

Rees, Michael A., Jonathan E. Kopke, Ronald P. Pelletier, Dorry L. Segev, Matthew E. Rutter, Alfredo J. Fabrega, Jeffrey Rogers, Oleh G. Pankewycz, Janet Hiller, Alvin E. Roth, Tuomas Sandholm, Utku Ünver, and Robert A. Montgomery. 2009. “A Non- 
Simultaneous Extended Altruistic Donor Chain.” NEJM, 360(11): 1096-1101.

Rees, Michael A., Mark A. Schnitzler, E. Y. Zavala, James A. Cutler, Alvin E. Roth, F. Dennis Irwin, Stephen W. Crawford, and Alan B. Leichtman.. "Call to develop a standard acquisition charge model for kidney paired donation." American Journal of Transplantation 12.6 (2012): 1392-1397.

Roth, Alvin E., Tayfun Sönmez, and M. Utku Ünver. 2004. “Kidney Exchange.” Quarterly Journal of Economics 119 (2): 457-88.

Roth, Alvin E., Tayfun Sönmez, and M. Utku Ünver. 2005a. “A Kidney Exchange Clearinghouse in New England." American Economic Review 95 (2): 376-80.

Roth, Alvin E., Tayfun Sönmez, M. Utku Ünver, Francis L. Delmonico, and Susan L. Saidman, "Utilizing List Exchange and Undirected Good Samaritan Donation through “Chain” Paired Kidney Donations,"' American Journal of Transplantation, 6, 11, November 2006, 2694-2705

Roth, Alvin E., 2007. Repugnance as a constraint on markets. J. Econ. Perspect. 21 (3): 37-58. Sandel, Michael J. What money can't buy: the moral limits of markets. Macmillan, 2012.

Sandel, Michael J. 2013. "Market Reasoning as Moral Reasoning: Why Economists Should Reengage with Political Philosophy." The Journal of Economic Perspectives 27.4: 121-140.

Thaler, Richard H. 2009. “Opting in versus Opting out.” The New York Times, September 26. Organ Procurement and Transplantation Network. 12/24/2013. optn.transplant.hrsa.gov/data/ Wolfe, Robert A., Valarie B. Ashby, Edgar L. Milford, Akinlolu O. Ojo, Robert E. Ettenger, Lawrence Y.C. Agodoa, Philip J. Held, and Friedrich K. Port. 1999. "Comparison of mortality in all patients on dialysis, patients on Dialysis awaiting transplantation, and recipients of a first cadaveric transplant" NEJM 341.23: 1725-1730. 